\title{
The genetic mating system of a sea spider with male-biased sexual size dimorphism: evidence for paternity skew despite random mating success
}

\author{
Felipe S. Barreto • John C. Avise
}

Received: 16 November 2010 /Revised: 2 February 2011 / Accepted: 23 February 2011 /Published online: 12 March 2011

(C) The Author(s) 2011. This article is published with open access at Springerlink.com

\begin{abstract}
Male-biased size dimorphism is usually expected to evolve in taxa with intense male-male competition for mates, and it is hence associated with high variances in male mating success. Most species of pycnogonid sea spiders exhibit female-biased size dimorphism, and are notable among arthropods for having exclusive male parental care of embryos. Relatively little, however, is known about their natural history, breeding ecology, and mating systems. Here we first show that Ammothella biunguiculata, a small intertidal sea spider, exhibits malebiased size dimorphism. Moreover, we combine genetic parentage analysis with quantitative measures of sexual selection to show that male body size does not appear to be under directional selection. Simulations of random mating revealed that mate acquisition in this species is largely driven by chance factors, although actual paternity success is likely non-randomly distributed. Finally, the opportunity for sexual selection $\left(I_{\mathrm{s}}\right)$, an indirect metric for the potential strength of sexual selection, in A. biunguiculata males was less than half of that estimated in a sea spider with femalebiased size dimorphism, suggesting the direction of size
\end{abstract}

Communicated by L. Simmons

Electronic supplementary material The online version of this article (doi:10.1007/s00265-011-1170-x) contains supplementary material, which is available to authorized users.

F. S. Barreto · J. C. Avise

Department of Ecology and Evolutionary Biology,

University of California,

Irvine, CA 92697, USA

\section{F. S. Barreto $(\triangle)$}

Marine Biology Research Division, Scripps Institution of

Oceanography, University of California-San Diego,

La Jolla, CA 92093, USA

e-mail: fbarreto@ucsd.edu dimorphism may not be a reliable predictor of the intensity of sexual selection in this group. We highlight the suitability of pycnogonids as model systems for addressing questions relating parental investment and sexual selection, as well as the current lack of basic information on their natural history and breeding ecology.

Keywords Pycnogonida $\cdot$ Microsatellites $\cdot$ Opportunity for selection $\cdot$ Paternity analysis $\cdot$ Polygynandry $\cdot$ Sexual size dimorphism

\section{Introduction}

Sex differences in body size are often a conspicuous aspect of taxa experiencing sexual selection (Andersson 1994) and have been shown to greatly influence (and to be influenced by) animal mating systems (Blanckenhorn 2005; Fairbairn et al. 2007). Male-biased size dimorphism (MSD) is generally explained by size advantage in male-male competition for mates, and it is often associated with highly polygynous species that exhibit skewed male reproductive success (Le Boeuf and Reiter 1988; Boness et al. 1993; Andersson 1994). While this is perhaps the most wellunderstood relationship between sexual size dimorphism and mating systems, such generalizations are often restricted to birds and mammals (Payne 1984; Andersson 1994; Weckerly 1998; Blanckenhorn 2005); most other taxa exhibit much greater variation in the degree and direction of sexual size dimorphism and size-related selective pressures (Fairbairn et al. 2007). Female-biased size dimorphism (FSD), for example, can be explained by fecundity selection on females (Darwin 1871; Williams 1966), sexual selection for smaller male sizes during scramble competition for mates (Kelly et al. 2008; Moya- 
Laraño et al. 2009), or a combination of the two selective pressures (Blanckenhorn 2005).

Other ecological or organismal factors can further obscure the causal link between sexual size dimorphism and mating systems. Postzygotic care of offspring, for instance, may alter the sexually selected advantage of large body size in males (Andersson 1994; Shuster and Wade 2003). Among harvestmen (Arachnida: Opiliones) with paternal care, MSD is observed in species in which body size influences the outcome of fights for high-quality oviposition sites (Machado et al. 2004). In species in which females prefer to mate with egg-guarding males, male body size does not affect reproductive success, and little to no sexual dimorphism is observed (Nazareth and Machado 2010). Male parental investment in offspring care is sometimes large enough to offset the initially higher maternal investment (in egg size), making the potential reproductive rate of males to be lower than that of females (Clutton-Brock and Vincent 1991). Such taxa exhibit sexrole reversal (i.e., stronger sexual selection on females) and often have female-biased size dimorphism (Oring et al. 1991; Vincent et al. 1992; Butchart 2000; Jones et al. 2001). Taxa that exhibit uniparental postzygotic care by males hence provide unique opportunities for evaluating proffered relationships between sexual dimorphism, sexual selection, and mating systems.

Empirical studies of mating systems and sexual selection in taxa with paternal care, however, have focused largely on vertebrates, even though this behavior has evolved independently in at least 17 invertebrate groups (Clutton-Brock 1991; reviewed in Tallamy 2001). Among arthropods, the Class Pycnogonida (Chelicerata) is notable for exhibiting widespread male parental care of offspring. Egg-carrying males have been observed in nearly all of the 1,200+ species of pycnogonids, or sea spiders. Using a pair of specialized appendages (ovigers), each male pycnogonid collects the externally fertilized eggs into distinct clusters and carries them until hatching (King 1973; Bain and Govedich 2004a), which can take up to 3 months in some species (Tomaschko et al. 1997). Sexual size dimorphism is female biased in most pycnogonids (Hedgpeth 1941; Arnaud and Bamber 1987; Tomaschko et al. 1997; Bain and Govedich 2004a) and female-female competition for mates has been documented in at least one species (Propallene saengeri; Bain and Govedich 2004b). Despite these attractive features, pycnogonid mating systems remain poorly known, and patterns of mating and reproductive success in natural populations have only been investigated genetically in two other species (Barreto and Avise 2008, 2010).

The incorporation of molecular genetic methods in field studies has revealed numerous discrepancies between behavioral and realized reproductive success (Birkhead and Møller 1992; Philipp and Gross 1994; Avise et al. 2002). In pycnogonids, for example, genetic paternity assays revealed for the first time unambiguously that females mate with multiple males and that variation in developmental stage among egg clusters is a poor predictor of the number of mates a male acquired (Barreto and Avise 2008, 2010). The coupling of genetic parentage analysis with quantitative metrics based on opportunity for selection theory (Crow 1958; Wade 1979; Lande and Arnold 1983) and Bateman's principles (Bateman 1948; Arnold and Duvall 1994) have been repeatedly useful in comparisons of mating systems that show differences due to sex ratios (Jones et al. 2002, 2004), geography (Mobley and Jones 2009), sex roles (Jones et al. 2000), territoriality (Fincke 1988; McVey 1988), and size dimorphism (Howard 1988; Vanpé et al. 2008). Despite criticisms (Grafen 1987; Hubbell and Johnson 1987; Kokko et al. 1999), these measures provide, at the very least, standardized quantifications of mating systems for which we have no a priori knowledge of how sexual selection occurs (Shuster and Wade 2003).

In this study, we combine DNA microsatellite markers, morphometric measurements, and quantitative metrics of selection to quantify the distribution of mating and reproductive success and the degree of sexual size dimorphism among individuals in a natural population of Ammothella biunguiculata (Ammotheidae), a minute intertidal pycnogonid for which little was known regarding the mating system. Moreover, we test the general prediction that males of species with MSD should experience stronger sexual selection than those of species with female-biased size dimorphism (Ghiselin 1974; Andersson 1994) by comparing measures from selection theory to those of a pycnogonid with FSD (Barreto and Avise 2008).

\section{Materials and methods}

Study species and collection of samples

Ammothella biunguiculata is a small $(\sim 1 \mathrm{~mm}$ body length) pycnogonid found commonly under rocks in the intertidal and subtidal zones of the Pacific coast of North America. Males in this species carry eggs arranged into one to many physically distinct, spherical egg clusters attached to the ovigers, very similar to the arrangement found in Ammothea hilgendorfi (see Fig. 1 in Barreto and Avise 2008).

We collected a total of 162 individuals from under small rocks in Corona del Mar State Beach (33 $35^{\prime} \mathrm{N}, 117^{\circ} 52^{\prime} \mathrm{W}$ ), California, in October and November 2008, and January and March 2009 . The adult sex ratio $\left[N_{\text {females }} /\left(N_{\text {females }}+N_{\text {males }}\right)\right]$ did not deviate from unity during our collection period (range, 0.40-0.47; binomial test, $P>0.31$ for all months). Of 64 males that carried egg clusters (total $n=189$ clusters), 
45 were brought live to the laboratory; all other individuals collected were immediately preserved in $95 \%$ ethanol. Clusters were separated from each other and from their guardian males, and kept separately in $1.5-\mathrm{ml}$ centrifuge tubes containing filtered room-temperature seawater. Males were then preserved in ethanol. Tubes were inspected every 2-3 days for newly hatched larvae. When larvae were present, they were transferred collectively into a 2-ml tube containing $95 \%$ ethanol until genetic analysis. We continued to inspect egg clusters until all larvae had hatched or until no further development was noticed for at least 7 days. Prior to genetic analysis, a random sample of the larvae stored in ethanol was transferred to a petri dish and larvae were pipetted individually to the bottom of a PCR plate.

Genetic marker development and parentage analysis

Isolation of microsatellite markers for A. biunguiculata followed the enrichment protocol of Hamilton et al. (1999), with modifications (Hauswaldt and Glenn 2003), and was described for a pycnogonid elsewhere (Barreto and Avise 2008). Genomic DNA from adults was extracted from entire specimens, after morphometric analysis (see below), using a standard phenol-chloroform-isoamyl protocol (Milligan 1998). To extract DNA from individual larvae, $12 \mu \mathrm{l}$ of lysis buffer $(10 \mathrm{mM}$ Tris- $\mathrm{HCl} \mathrm{pH} 8.3,50 \mathrm{mM}$ $\mathrm{KCl}, 0.5 \%$ Tween-20, $250 \mu \mathrm{g} / \mathrm{ml}$ proteinase $\mathrm{K}$ ) were added to each well of the PCR plates containing the samples. Plates were then incubated at $55^{\circ} \mathrm{C}$ for $2.5 \mathrm{~h}$, followed by heating to $95^{\circ} \mathrm{C}$ for $15 \mathrm{~min}$ to deactivate the proteinase. Microsatellite amplification reactions were performed as described for another pycnogonid (Barreto and Avise 2008).

Five microsatellite loci were chosen based on their polymorphism information, ease of scoring, and reproducibility (Table 1). We used the Markov chain method implemented in the program GENEPOP (Raymond and Rousset 1995) to check for deviations from HardyWeinberg and linkage equilibria, and we controlled for type-I errors from multiple testing with sequential DunnSidák's adjustments of $\alpha$ values (Sokal and Rohlf 1995). For parentage assays, 15-20 larvae per cluster were randomly selected. Maternal genotypes were deduced from each egg cluster after subtracting the guardian male's alleles. Deduced genotypes were then compared to each other and to those of collected females using the Microsatellite Toolkit (Park 2001) in order to detect identical multilocus genotypes.

\section{Morphometric assessment}

Prior to DNA extraction, we took digital photographs under a dissecting microscope of the second ambulatory leg and dorsal full-trunk view of every undamaged adult specimen, and of the left oviger of males. Using ImageJ software (NIH), we took the following linear measurements (to the nearest $0.01 \mathrm{~mm}$ ): trunk length (distance between eye tubercle and base of abdomen), trunk width (distance between the edges of the lateral processes on the second trunk segment), femur length, mid-femur height, and length of ovigers (from males only). Since there is no standardized method for describing pycnogonid size variation, we chose those features to encompass the different ways in which these measurements are performed (Hedgpeth 1941; Arnaud and Bamber 1987; Tomaschko et al. 1997). In order to avoid including immature individuals in our selection and dimorphism analyses, we used morphological features assumed to be indicators of sexual maturity (Bain and Govedich 2004a). Among males, we kept only individuals whose ovigers exhibited the distinctly modified terminal segments. Finally, we retained only females whose

Table 1 Features of five microsatellite loci characterized for the pycnogonid Ammothella biunguiculata

\begin{tabular}{|c|c|c|c|c|c|}
\hline Locus & Primer sequences $\left(5^{\prime}-3^{\prime}\right)$ & Repeat motif ${ }^{a}$ & No. of alleles & $\mathrm{H}_{\mathrm{o}}$ & $\operatorname{PrE}^{\mathrm{b}}$ \\
\hline$A b i-55$ & $\begin{array}{l}\text { F: /FAM/TCTGCAAGCTGCCTGATT } \\
\text { R: TGGGAACAAACATAGGTGCC }\end{array}$ & $(\mathrm{CT})_{23}$ & 11 & 0.76 & 0.504 \\
\hline Abi-67 & $\begin{array}{l}\text { F: /HEX/ATTGTGGACGGTCTGAAAGG } \\
\text { R: GCACGCATTACCATCGAAAC }\end{array}$ & $(\mathrm{GA})_{28}$ & 23 & 0.88 & 0.804 \\
\hline Abi-132 & $\begin{array}{l}\text { F: /NED/CTTCTTACTTCCGCCGTTGT } \\
\text { R: TGTTGGTGTCTGGAACTGAC }\end{array}$ & $(\mathrm{GA})_{29}$ & 25 & 0.93 & 0.809 \\
\hline$A b i-160$ & $\begin{array}{l}\text { F: GATGGTCAGTCCTCCGATACTA } \\
\text { R: /FAM/CGAACAACTTCGATGCAACAAC }\end{array}$ & $(\mathrm{CCAT})_{52}$ & 60 & 0.94 & 0.942 \\
\hline Abi-225 & $\begin{array}{l}\text { F: CCATCAATTATAGGGCTCTGGC } \\
\text { R: /HEX/TCGTTTGCCAACAACCT }\end{array}$ & $(\mathrm{TGA})_{19}$ & 14 & 0.79 & 0.610 \\
\hline
\end{tabular}

Values in the last three columns were estimated from a sample of 143 adult and sub-adult individuals. PCR products of loci were pooled at equal proportions and $1 \mu \mathrm{l}$ of the mixture was used for electrophoresis on an ABI PRISM 3100 Genetic Analyzer (Applied Biosystems)

${ }^{a}$ Number and sequence of microsatellite repeat found on original clones

${ }^{\mathrm{b}}$ Probability of genetic exclusion under the assumption that one parent was known. Combined probability is 0.9996, based on Jamieson and Taylor (1997) 
gonopores (located on the ventral side of the second coxa) were visible. We used multivariate analysis of variance (MANOVA) and subsequent ANOVA to assess whether there were, respectively, overall differences and univariate differences in morphological traits between the sexes.

\section{Selection analyses}

Components of fitness were the mating success (number of mates) and reproductive success (number of offspring sired) per male. The number of hatched larvae and the number of unhatched eggs remaining on each egg cluster were counted under a microscope and summed to obtain the number of offspring per cluster. Values of mating and reproductive successes were then standardized to a relative scale (with mean of unity) by dividing the absolute values by their respective means. We estimated the potential, or upper limit of directional selection by calculating the opportunity for selection $\left(I_{\mathrm{m}}\right)$ and the opportunity for sexual selection $\left(I_{\mathrm{s}}\right)$ following the methods of Wade (1979) and Wade and Arnold (1980). These are represented, respectively, by the standardized variance in reproductive success (variance in number of offspring divided by the squared mean number of offspring, $\sigma_{r s}^{2} / \bar{X}_{r s}^{2}$ ) and the standardized variance in mating success $\left(\sigma_{m s}^{2} / \bar{X}_{m s}^{2}\right)$. We also obtained the Bateman gradient, or sexual selection gradient by means of a linear least-squares regression of relative reproductive success on relative mating success (Arnold and Duvall 1994).

Finally, we used the statistical framework of Lande and Arnold (1983) to obtain estimates of the intensity of directional selection on morphological characters of male $A$. biunguiculata. After checking for normality (Shapiro-Wilk's test, $P>0.05$ ), variables were standardized to a mean of zero and standard deviation of unity. Standardized directional selection gradients $\left(\beta^{\prime}\right)$ were estimated as the partial regression coefficients from a multiple regression of each relative fitness component (mating or reproductive success) on the morphological traits (Lande and Arnold 1983). Mature individuals with no detected matings (i.e., those who carried no egg clusters) were included in the above analyses.

Test of random mating and paternity

A nonzero variance in mating success alone, even when few or many individuals fail to mate, should not be interpreted as unambiguous evidence of strong sexual selection in a sex; stochastic factors can produce intrapopulation variance in reproductive success (Hartley and Shepherd 1995; Sutherland 1985; Focardi and Tinelli 1996; Friedl and Klump 2005; Brommer et al. 2007). We therefore tested the null hypothesis that all males had an equal probability of acquiring mates. To generate a distribution of mating success according to this null model, we performed a simple simulation using two parameters observed in our sample: $k$, the array of males included in the estimate of $I_{\mathrm{s}}$ above and $j$, the total number of female mates detected, summed across all males. In each simulated mating bout, $k$ was sampled $j$ times with replacement, keeping track of the identity of the males. The number of times each male mated (i.e., was sampled) was then tallied, and these values were distributed into categories of mating success (zero mates, one mate, two mates, etc.). The simulation was run 10,000 times, after which the categories were summed across replicates to obtain the expected distribution of mating success under random mating. The fit of the observed and expected distributions was assessed by way of a randomization test with 5,000 replicates and following a $\chi^{2}$ distribution (with categories pooled so that expected values were $\geq 1$ ).

Since females varied greatly in how many eggs they laid per mate (range 15-256), we also tested the null hypothesis that progeny were randomly distributed among males by performing another simulation. Instead of using the number of progeny per male as a measure of reproductive success, we used the number of clusters carried, since the latter was a good predictor of the former $\left(r^{2}=0.83, N=45, P<\right.$ 0.0001 ) and permitted a natural "binning" of progeny. We assigned $k$ to be the total number of males in our sample, and $j$ to be the total number of clusters, summed across males. This simulation was run as above. Both simulations were performed in R 2.6.2 (R Development Core Team), and standardized variances were calculated from each (referred to as $I_{s}^{*}$ and $I_{m}^{*}$ ).

\section{Results}

\section{Genetic markers}

The five microsatellite loci developed for A. biunguiculata provided sufficient power for unambiguous assignment of paternity and maternity, with a combined probability of genetic exclusion >0.999 (Table 1). After Dunn-Sidák's correction for multiple testing, no pair of loci showed detectable linkage disequilibrium, and all but one locus conformed to Hardy-Weinberg expectations. Locus Abi160 exhibited a significant heterozygote deficit (Fisher's exact test, $P=0.008$ ), likely due to null alleles. Null allele frequency was estimated to be 0.023 (Brookfield 1996). Although null alleles, even at such low frequency, can cause bias in paternity assignments (Dakin and Avise 2004), we readily detected the manifestation of a null allele in one progeny array.

We also uncovered 13 parent-progeny mismatches that were better explained as de novo mutations; each mismatch 
occurred in a different progeny array, and involved a single allele and a single offspring from each array. These mutations occurred at all loci analyzed (range 1-4 per locus), and, given our sampling effort, we estimate the mutation rate to be roughly $6.9 \times 10^{-4}$ per gamete per locus.

Mating patterns and paternity variance

More than $76 \%$ of the 84 males collected carried between one and nine egg clusters, with a mean $( \pm \mathrm{SE})$ of $60.3(2.8)$ progeny per cluster. A total of 1,720 larvae, hatched from the 137 egg clusters incubated, were successfully genotyped at all five loci. Based on their multilocus genotypes, all progeny assayed were consistent with having been sired by their respective male guardian. Subtraction of the paternal allele from each offspring allowed us to deduce the multilocus genotypes for every cluster's dam. Consistent with findings on two other pycnogonids (Nakamura and Sekiguchi 1980; Barreto and Avise 2008), progeny found on the same egg cluster were invariably full siblings. Multiple clusters carried by a given male, though often laid by different females, sometimes shared the same dam. For instance, two males in our sample each carried nine clusters; one of them had nine mates but the other had a total of four mates. Genetic parentage analysis is detailed in Table S1 (electronic supplemental materials).

Our genetic investigation revealed that mated $A$. biunguiculata males acquired one to nine mates $\left(\bar{X}_{m s} \pm \mathrm{SD}=1.81 \pm 1.67, n=59\right.$, including unmated males), yielding an estimated $I_{\mathrm{s}}=0.85$. Although the one male with nine mates observed was a highly unlikely find $(P=0.006)$, the overall distribution of mating success did not deviate significantly from random expectations $\left(\chi^{2}=3.62\right.$, $P>0.37 ; I_{s}^{*}=0.55$; Fig. 1a). Observed distribution of reproductive success, however, departed significantly from randomness $\left(\chi^{2}=28.57, P<0.0001 ; I_{m}^{*}=0.44\right.$; Fig. $\left.1 b\right)$. Specifically, males that received seven or more clusters were observed more frequently than expected by chance $(P<0.01)$, and more males had zero reproductive success (i.e., carried no eggs) than could be accounted for by random mating $(P<$ 0.0001 ; Fig. 1b). Interestingly, males that had more than one mate received significantly more eggs per female than males with a single mate $(t=2.25, d f=43, P=0.024$; Fig. 2). Finally, $I_{\mathrm{m}}=1.12$, based on number of progeny sired per male $\left(\bar{X}_{r s} \pm \mathrm{SD}=143.3 \pm 151.6, n=59\right.$, including unmated males).

From the 137 clusters assayed, we reconstructed 71 dam genotypes, 18 of which matched the genotypes of collected females (with probability of genetic identity ranging from $10^{-14}$ to $10^{-8}$; Table S1). Our genetic analysis documented several instances of multiple mating by females, with $34 \%$ of deduced dam genotypes found in clusters from more than one male. Two females, one of which was collected,
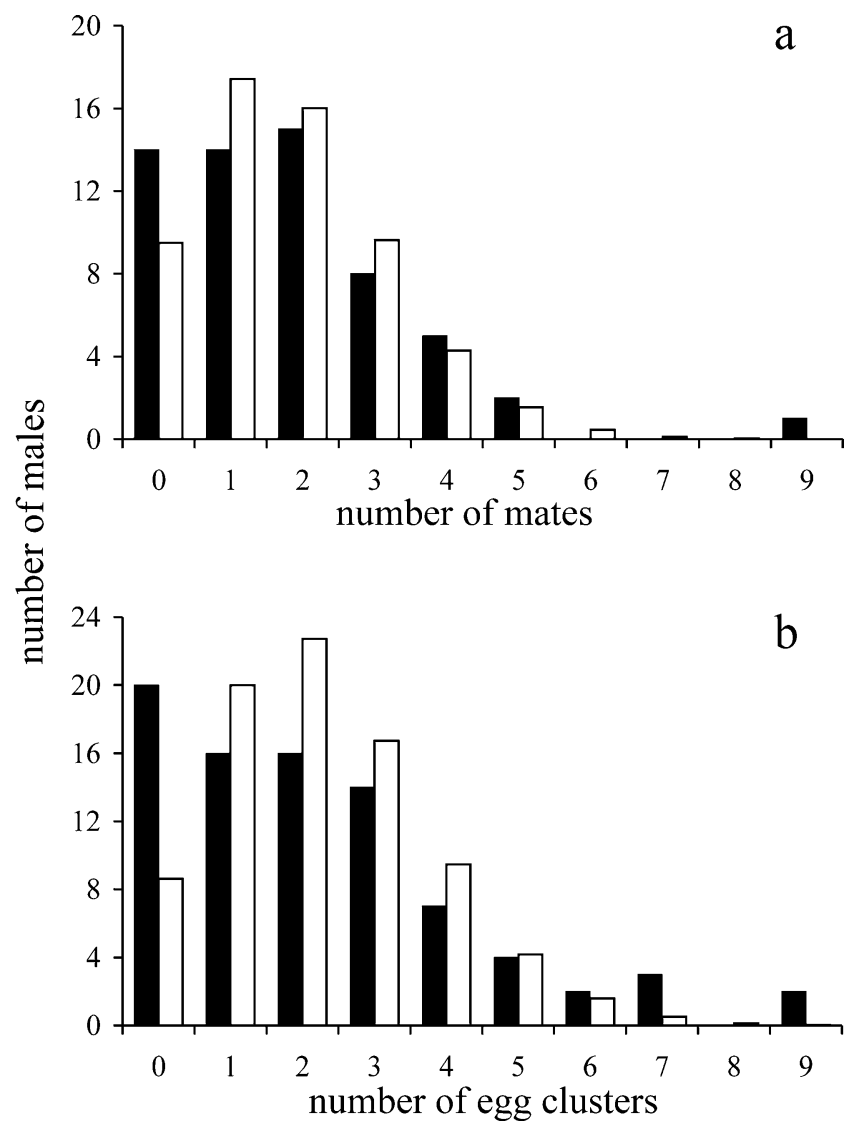

Fig. 1 Distribution of mating success (a) and paternity success (b) of male Ammothella biunguiculata. Observed numbers (black bars) were compared to frequencies expected following simulations of random mating success and random paternity success, respectively (white bars)

mated with as many as four different males. Given the relatively low success in assignment of maternity, we could not confidently estimate the distribution of mating success of females. The highest number of eggs laid by a single female in our sample was 396, distributed across six clusters (female D14 in Table S1). While the number of eggs deposited per cluster varied by an order of magnitude (range 15-155), it did not differ significantly $(t=-0.68$, $d f=71, P=0.48$ ) between females that laid one cluster

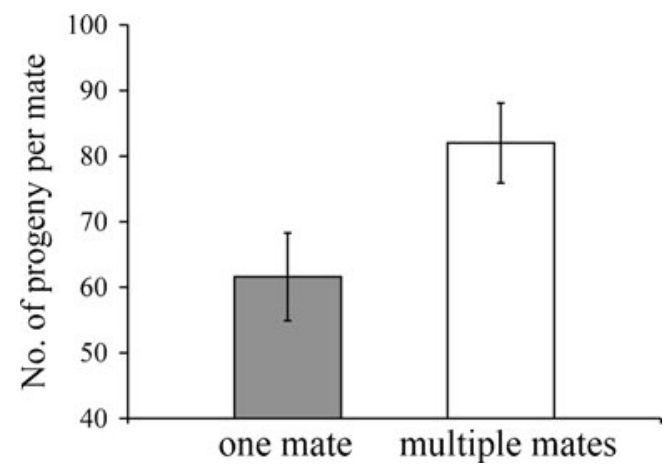

Fig. 2 Mean $( \pm \mathrm{SE})$ number of eggs that males received per female according to whether they acquired one or more mates 
$(\bar{X} \pm \mathrm{SE}=60 \pm 4.5)$ and those that laid multiple clusters $(64 \pm 3.6)$.

Sexual size dimorphism and selection gradients

Summary morphometric descriptions are found in Table 2 . The initial MANOVA indicated an overall significant difference between the sexes (Wilk's $\lambda=0.34, F_{4,99}=$ 48.3, $P<0.0001)$. Male $A$. biunguiculata had trunks that were on average $7 \%$ longer and wider than those of females $\left(F_{1,118}=20.1, P<0.0001\right)$. With regard to leg traits, the femora of females were on average $16 \%$ thicker than those of males $\left(F_{1,118}=79, P<0.0001\right)$, even though no difference between the sexes was detected in femur length $\left(F_{1,118}=2.3, P=0.13\right)$.

The relative reproductive success of males was strongly dependent on mate acquisition, as evidenced by the significantly positive Bateman gradient $\left(F_{1,56}=168\right.$, $P<0.0001$; Table 3). According to standardized selection gradients, however, there was no evidence that variation in mating or reproductive success was based on any of the body size traits measured (all tests: $F<0.26, P>0.33$; Table 3). Size traits were also not different between unmated and mated males when the latter were pooled into one group ( $t$ statistic range $-0.23-0.70, P>0.48$ ).

\section{Discussion}

Besides exhibiting a taxonomically widespread expression of exclusive male parental care, pycnogonids vary greatly in habitat preference, egg-brooding configuration and duration, developmental time, mating behaviour, and size dimorphism (Arnaud and Bamber 1987; Bain and Govedich 2004a), all of which are known to influence features of mating systems (Emlen and Oring 1977; Clutton-Brock 1988; Andersson 1994; Avise et al. 2002; Shuster and Wade 2003). Several authors have hence proffered pycnogonids as

Table 2 Mean ( $95 \%$ confidence intervals) of trunk and femur measurements for male and female Ammothella biunguiculata (Pycnogonida: Ammotheidae) from Newport Beach, California

\begin{tabular}{lll}
\hline & \multicolumn{2}{l}{ Mean $(95 \% \mathrm{CI})$ in millimeters } \\
\cline { 2 - 3 } & Males $(n=67)$ & Females $(n=53)$ \\
\hline Trunk length* $^{*}$ & $1.09(1.07-1.11)$ & $1.02(0.99-1.03)$ \\
Trunk width* $_{\text {Femur length }}{ }^{\mathrm{a}}$ & $0.74(0.73-0.75)$ & $0.69(0.68-0.70)$ \\
Femur height* & $0.71(0.70-0.72)$ & $0.73(0.71-0.75)$ \\
\hline
\end{tabular}

$* P<0.0001$, ANOVA

${ }^{a}$ Not significant, ANOVA
Table 3 Standardized linear selection gradients in field-collected males of the pycnogonid Ammothella biunguiculata

\begin{tabular}{lcl}
\hline Trait & $\beta^{\prime} \pm \operatorname{SE}(P$ value $)$ & \\
\cline { 2 - 3 } & Mating success & Reproductive success \\
\hline Trunk length $(n=50)$ & $0.06 \pm 0.13(0.77)$ & $0.09 \pm 0.16(0.61)$ \\
Femur length $(n=50)$ & $0.04 \pm 0.13(0.87)$ & $0.05 \pm 0.21(0.97)$ \\
Oviger length $(n=49)$ & $0.12 \pm 0.12(0.33)$ & $-0.27 \pm 0.64(0.41)$ \\
No. of mates $(n=59)$ & - & $0.98^{\mathrm{a}} \pm 0.08(<0.0001)$ \\
\hline
\end{tabular}

Two measures of fitness (relative mating success and reproductive success) were regressed on phenotypic predictors using multiple regressions

${ }^{\mathrm{a}}$ This coefficient represents the sexual selection, or Bateman gradient (Bateman 1948; Arnold and Duvall 1994), represented as $\beta_{\mathrm{ss}}$

an ideal system for testing predictions from sexual selection, mating system, and parental investment theories (Tallamy 2001; Shuster and Wade 2003; Bain and Govedich 2004a). Nevertheless, relatively little is known about pycnogonid natural history, and we are aware of only two other pycnogonid species for which the natural mating system has been investigated with genetic markers (A. hilgendorfi, Barreto and Avise 2008; Pycnogonum stearnsi, Barreto and Avise 2010). As in those two species, our study revealed that both sexes in A. biunguiculata routinely mate with multiple mates within the period of time it takes a male to brood one cluster of eggs. Therefore, this species is polygynandrous (sensu Andersson 1994).

Most pycnogonid species for which sexual size dimorphism has been documented (generally reported as body or leg length) exhibited FSD (Hedgpeth 1941; Arnaud and Bamber 1987; Tomaschko et al. 1997; Bain and Govedich 2004a; Barreto and Avise 2008). Among the traits measured in this study, however, femur height was the only one that was greater in females than in males. This is not surprising since most of a pycnogonid's reproductive system is distributed as branches into some or all of the ambulatory legs, and yolk deposition in ova occurs in the female femur (King and Jarvis 1970; Arnaud and Bamber 1987). After excluding femur height from the dataset, overall size remained significantly different between the sexes (MANOVA, Wilk's $\lambda=0.60, F_{3,100}=22.2, P<$ 0.0001). Ammothella biunguiculata hence exhibits malebiased sexual size dimorphism, albeit to a weak degree ( $\sim 7 \%$ difference in trunk dimensions).

Male-biased size dimorphism is thought to evolve primarily through intense male-male competition for mates, and it is generally predicted to be associated with highly polygynous mating systems (Darwin 1871; Clutton-Brock 1989; Andersson 1994). For example, studies of strongly size-dimorphic bighorn sheep and Northern elephant seals have yielded estimates of $I_{\mathrm{m}}$ ranging from 2.45 to 27.00 
(Le Boeuf and Reiter 1988; Coltman et al. 2002). Concordantly, a positive relationship between increased opportunity for sexual selection and the degree of MSD has been observed, at least in ungulates (Vanpé et al. 2008). The influence of male body size on relative reproductive success in such highly dimorphic species generally follows expectations (reviewed in Andersson 1994), but the strength of this relationship in taxa with low MSD is not as well documented. Our estimates of $I_{\mathrm{m}}$ and $I_{\mathrm{s}}$ are comparable to those from other taxa with similar degrees of sexual size dimorphism, such as the roe deer (Vanpé et al. 2008) and the harbor seal (Coltman et al. 1998). Also, in agreement with those studies is our finding that male body size did not appear to explain variation in mating or reproductive success. Some pycnogonids have been observed to use ovigers in courtship (reviewed in Bain and Govedich 2004a). In A. biunguiculata, the length of ovigers was not a good predictor of fitness. It is likely that behavioral or morphological traits not examined in this study are the target of sexual selection in A. biunguiculata. Alternatively, the influence of male body size on mating success may vary with seasonal or geographical changes in mate density or availability, as observed in some fishes (Jirotkul 1999; Borg et al. 2006), spiders (Rittschof 2010), and water striders (Fairbairn 1988). We emphasize, however, that our sample size is well below what it is generally needed to detect even moderate levels of directional or stabilizing selection in natural populations (Conner 2001; Kingsolver et al. 2001; Hersch and Phillips 2004).

Males of species with MSD are ordinarily expected to be under stronger sexual selection than those of species with FSD (Vollrath and Parker 1992; Andersson 1994). Cases in which genetic parentage was assessed, however, have generated conflicting results (Schulte-Hostedde et al. 2004; Kelly et al. 2008; Rossiter et al. 2006; Burland et al. 2001), but these comparisons encompass a wide range of taxonomic groups. We hence compared our genetic parentage results to those for A. hilgendorfi (Barreto and Avise 2008), a species in the same family (Ammotheidae) and with very similar egg-brooding arrangement and behaviour as A. biunguiculata, but in which females are larger than males in trunk and leg lengths (by $5 \%$ and $15 \%$, respectively; Barreto and Avise 2008). The standardized Bateman gradient of male A. hilgendorfi was also significantly positive $\left(\beta_{\mathrm{ss}} \pm \mathrm{SE}=1.15 \pm 0.14, F_{1,30}=63.6, P<\right.$ $0.0001, n=32$ ), and it did not differ significantly from that of $A$. biunguiculata (ANCOVA $F_{3,86}=1.14, P=0.39$; Table 3). This suggests that, in both of these species, parental care has not prevented males from pursuing additional mates and increasing their reproductive output. In contrast, estimated $I_{\mathrm{s}}$ and $I_{\mathrm{m}}$ for $A$. hilgendorfi (Barreto and Avise 2008) were over twofold higher (2.02 and 3.91, respectively; 0.85 and 1.12 in A. biunguiculata, this study).
The direction of sexual size dimorphism hence may not be a reliable predictor of the intensity of sexual selection among pycnogonids. Factors that can affect the causal link between reproductive skew and sexual size dimorphism include, for instance, the potential reproductive rate of each sex (Clutton-Brock and Vincent 1991), the intensity of fecundity selection on females (Darwin 1871; Williams 1966), the presence of alternative reproductive tactics (Gross 1996; Avise et al. 2002), and sex-biased mobility (Hakkarainen et al. 1996; Kelly et al. 2008). No such topics have yet been addressed in pycnogonids.

Relatively few studies have tried to account for the influence of random processes in producing observed reproductive skews, despite strong evidence that such factors often explain major components of variation even in highly polygynous systems (Hartley and Shepherd 1995; Focardi and Tinelli 1996; Friedl and Klump 2005). Our analyses revealed that mate acquisition in male $A$. biunguiculata occurred largely at random. Simulated random mating suggests that at least $64 \%$ (by the ratio $I_{s}^{*} / I_{s}$ ) of the variance in mating success in our sample can be accounted for by chance factors. Mating success did not, however, accurately reflect the number of progeny sired, since the latter showed a highly non-random skew. This suggests that some males were able to acquire more eggs per mate than expected by chance. Congruent with this prediction, we found evidence that males who acquired two or more mates sired, on average, $30 \%$ more progeny per mate than did males with one mate. Together, these findings are consistent with a scenario in which mate acquisition by males is dependent mostly on random processes (e.g., encounter rate; Sutherland 1987), but once a male encounters a potential mate, the number of eggs he receives depends on whether he is already carrying previous clusters. In other words, eggcarrying may serve as an honest signal of quality, leading females to invest more eggs in matings with males that already carry at least one cluster than in matings with males carrying no eggs. This pattern of female preference for eggguarding males is common in several fish species (Ridley and Rechten 1981; Marconato and Bisazza 1986; Unger and Sargent 1988; Manica 2010), and has recently been demonstrated in reduviid bugs (Thomas and Manica 2005; Gilbert et al. 2010) and harvestmen (Nazareth and Machado 2010). This hypothesis warrants further investigation in pycnogonids by use of laboratory mating experiments. Finally, the null model we used in our simulation is likely oversimplified (Focardi and Tinelli 1996; Brommer et al. 2007); however, a more suitable null model requires more information about a system's breeding ecology than it is currently known in pycnogonids.

Current estimates of the opportunity for selection in pycnogonids (this study and Barreto and Avise 2008, 2010) yield values comparable to those in other polygynandrous 
systems (reviewed in Clutton-Brock 1988; Schulte-Hostedde et al. 2004; Vanpé et al. 2008). This index, however, measures the potential for selection to occur, but it does not reflect whether sexual selection has or will occur (Wade 1979). To demonstrate that sexual selection is indeed occurring, the phenotypic correlates of fitness must be identified (Lande and Arnold 1983; Downhower et al. 1987). Given the difficulty of detecting selection from field studies (Kingsolver et al. 2001), experimental manipulations in pycnogonids are warranted. In addition, the opportunity for selection is often more informative when it is partitioned among different components of the fitness continuum (McVey 1988; Webster et al. 1995; Shuster and Wade 2003; DuVal and Kempenaers 2008). Male pycnogonids have evolved the ability to carry large numbers of offspring, but it is not known, for instance, whether offspring survivorship is compromised by increased crowding. Elucidating basic aspects of pycnogonid breeding ecology should prove to be a rewarding venue for future research.

Acknowledgments We are grateful to the California Department of Fish and Game for issuing scientific collecting permits, and to N. Burley, A. Tatarenkov, and three anonymous reviewers for comments on the manuscript. Funding was provided by the School of Biological Sciences at UC-Irvine (to JCA) and by Sigma Xi (to FSB).

Open Access This article is distributed under the terms of the Creative Commons Attribution Noncommercial License which permits any noncommercial use, distribution, and reproduction in any medium, provided the original author(s) and source are credited.

\section{References}

Andersson MB (1994) Sexual selection. Princeton University Press, Princeton

Arnaud F, Bamber RN (1987) The biology of the Pycnogonida. In: Blaxter JHS, Southward AJ (eds) Advances in Marine Biology, vol 24, Academic Press. New York, NY, pp 1-96

Arnold SJ, Duvall D (1994) Animal mating systems: a synthesis based on selection theory. Am Nat 143:317-348

Avise JC, Jones AG, Walker D, De Woody JA et al (2002) Genetic mating systems and reproductive natural histories of fishes: lessons for ecology and evolution. Annu Rev Genet 36:19-45

Bain BA, Govedich FR (2004a) Courtship and mating behavior in the Pycnogonida (Chelicerata: Class Pycnogonida): a summary. Invert Reprod Dev 46:63-79

Bain BA, Govedich FR (2004b) Mating behaviour, female aggression, and infanticide in Propallene saengeri (Pycnogonida: Callipallenidae). Vic Nat 121:168-171

Barreto FS, Avise JC (2008) Polygynandry and sexual size dimorphism in the sea spider Ammothea hilgendorfi (Pycnogonida: Ammotheidae), a marine arthropod with brood-carrying males. Mol Ecol 17:4164-4175

Barreto FS, Avise JC (2010) Quantitative measures of sexual selection reveal no evidence for sex-role reversal in a sea spider with prolonged paternal care. Proc R Soc Lond B 277:2951-2956

Bateman AJ (1948) Intra-sexual selection in Drosophila. Heredity 2:349-368
Birkhead TR, Møller AP (1992) Sperm competition in birds: evolutionary causes and consequences. Academic Press, New York

Blanckenhorn WU (2005) Behavioral causes and consequences of sexual size dimorphism. Ethology 111:977-1016

Boness DJ, Bowen WD, Francis JM (1993) Implications of DNA fingerprinting for mating systems and reproductive strategies of pinnipeds. Symp Zool Soc Lond 66:61-93

Borg AA, Forsgren E, Amundsen T (2006) Seasonal change in female choice for male size in the two-spotted goby. Anim Behav 72:763-771

Brommer JE, Korsten P, Bouwman KM, Berg ML, Komdeur J (2007) Is extrapair mating random? On the probability distribution of extrapair young in avian broods. Behav Ecol 18:895-904

Brookfield JFY (1996) A simple new method for estimating null allele frequency from heterozygote deficiency. Mol Ecol 5:453-455

Burland TM, Barratt EM, Nichols RA, Racey PA (2001) Mating patterns, relatedness and the basis of natal philopatry in the brown long-eared bat, Plecotus auritus. Mol Ecol 10:1309-1321

Butchart SHM (2000) Population structure and breeding system of the sex-role reversed, polyandrous bronze-winger jacana Metopidius indicus. Ibis 142:93-102

Clutton-Brock TH (1988) Reproductive success. In: Clutton-Brock TH (ed) Reproductive success. University of Chicago Press, Chicago, pp 472-485

Clutton-Brock TH (1989) Mammalian mating systems. Proc R Soc Lond B 236:339-372

Clutton-Brock TH (1991) The evolution of parental care. Princeton University Press, Princeton

Clutton-Brock TH, Vincent ACJ (1991) Sexual selection and the potential reproductive rates of males and females. Nature 351:58-60

Coltman DW, Bowen WD, Wright JM (1998) Male mating success in an aquatically mating pinniped, the harbour seal (Phoca vitulina), assessed by microsatellite DNA markers. Mol Ecol 7:627-638

Coltman DW, Festa-Bianchet M, Jorgenson JT, Strobeck C (2002) Age-dependent sexual selection in bighorn rams. Proc R Soc Lond B 269:165-172

Conner JK (2001) How strong is natural selection? Trends Ecol Evol $16: 215-217$

Crow JF (1958) Some possibilities for measuring selection intensities in man. Hum Biol 30:1-13

Dakin EE, Avise JC (2004) Microsatellite null alleles in parentage analysis. Heredity 93:504-509

Darwin C (1871) The descent of man, and selection in relation to sex. John Murray, London

Downhower JF, Blumer LS, Brown L (1987) Opportunity for selection: an appropriate measure for evaluating variation in the potential for selection? Evolution 41:1395-1400

DuVal EH, Kempenaers B (2008) Sexual selection in a lekking bird: the relative opportunity for selection by female choice and male competition. Proc R Soc Lond B 275:1995-2003

Emlen ST, Oring LW (1977) Ecology, sexual selection, and the evolution of animal mating systems. Science 197:215-223

Fairbairn DJ (1988) Sexual selection for homogamy in the Gerridae: an extension of Ridley's comparative approach. Evolution 42:1212-122

Fairbairn DJ, Blanckenhorn WU, Székely T (eds) (2007) Sex, size and gender roles: evolutionary studies of sexual size dimorphism. Oxford University Press, Oxford

Fincke OM (1988) Sources of variation in lifetime reproductive success in a nonterritorial damselfly (Odonata: Coenagrionidae). In: Clutton-Brock TG (ed) Reproductive success. University of Chicago Press, Chicago, pp 24-43

Focardi S, Tinelli A (1996) May random processes explain mating success in leks? Behav Process 36:227-237 
Friedl TWP, Klump GM (2005) Sexual selection in the lek-breeding European treefrog: body size, chorus attendance, random mating and good genes. Anim Behav 70:1141-1154

Ghiselin MT (1974) The economy of nature and the evolution of sex. University of California Press, Berkeley

Gilbert JDJ, Thomas LK, Manica A (2010) Quantifying the benefits and costs of parental care in assassin bugs. Ecol Entomol $35: 639-651$

Grafen A (1987) Measuring sexual selection: why bother? In: Bradbury JW, Andersson MB (eds) Sexual selection: testing the alternatives. Wiley, New York, pp 221-233

Gross MR (1996) Alternative reproductive strategies and tactics: diversity within sexes. Trends Ecol Evol 11:92-98

Hakkarainen H, Huhta E, Lahti K, Lundvall P, Mappes T, Tolonen P, Wiehn J (1996) A test of male mating and hunting success in the kestrel: the advantage of smallness? Behav Ecol Sociobiol 39:375-380

Hamilton MB, Pincus EL, Di Fiore A, Flescher RC (1999) Universal linker and ligation procedures for construction of genomic DNA libraries enriched for microsatellites. Biotechniques 27:500-507

Hartley IR, Shepherd M (1995) A random female settlement model can explain polygyny in corn bunting. Anim Behav 49:11111118

Hauswaldt JS, Glenn TC (2003) Microsatellite DNA loci from the diamondback terrapin (Malaclemys terrapin). Mol Ecol Notes 3:174-176

Hedgpeth JW (1941) A key to the Pycnogonida of the Pacific coast of North America. Trans San Diego Soc Natur Hist 9:253-264

Hersch EI, Phillips PC (2004) Power and potential bias in field studies of natural selection. Evolution 58:479-485

Howard RD (1988) Reproductive success in two species of anurans. In: Clutton-Brock TH (ed) Reproductive success. University of Chicago Press, Chicago, pp 99-113

Hubbell SP, Johnson LK (1987) Environmental variance in lifetime mating success, mate choice and sexual selection. Am Nat 130:91-112

Jamieson A, Taylor SCS (1997) Comparisons of three probability formulae for parentage exclusion. Anim Genet 28:397-400

Jirotkul M (1999) Operational sex ratios influence preference and male-male competition in guppies. Anim Behav 58:287-294

Jones AG, Rosenqvist G, Berglund A, Arnold SJ, Avise JC (2000) The Bateman gradient and the cause of sexual selection in a sexrole-reversed pipefish. Proc R Soc B 267:677-680

Jones AG, Walker D, Avise JC (2001) Genetic evidence for extreme polyandry and extraordinary sex-role reversal in a pipefish. Proc R Soc B 268:2531-2535

Jones AG, Arguello JR, Arnold SJ (2002) Validation of Bateman's principles: a genetic study of sexual selection and mating patterns in the rough-skinned newt. Proc R Soc B 269:2533-2539

Jones AG, Arguello JR, Arnold SJ (2004) Molecular parentage analysis in experimental newt populations: the response of mating system measures to variation in the operational sex ratio. Am Nat 164:444-456

Kelly C, Bussière LF, Gwynne DT (2008) Sexual selection for male mobility in a giant insect with female-biased size dimorphism. Am Nat 172:417-423

King PE (1973) Pycnogonids. Hutchinson, London

King PE, Jarvis JH (1970) Egg development in a littoral pycnogonid Nymphon gracile. Mar Biol 7:294-304

Kingsolver JG, Hoekstra HE, Hoekstra JM, Berrigan D, Vignieri SN, Hill CE, Hoang A, Gibert P, Beerli P (2001) The strength of phenotypic selection in natural populations. Am Nat 57:245-261

Kokko H, Mackenzie A, Reynolds JD, Lindstrom J, Sutherland WJ (1999) Measures of inequality are not equal. Am Nat 72:358-382

Lande R, Arnold SJ (1983) The measurement of selection on correlated characters. Evolution 37:1210-1226
Le Boeuf BJ, Reiter J (1988) Lifetime reproductive success in northern elephant seals. In: Clutton-Brock TH (ed) Reproductive success. University of Chicago Press, Chicago, pp 344-362

Machado C, Requena GS, Buzatto BA, Osses F, Rossetto LM (2004) Five new cases of paternal care in harvestmen (Arachnida: Opiliones): implications for the evolution of male guarding in the Neotropical family Gonyleptidae. Sociobiology 44:577598

Manica A (2010) Female scissortail sergeants (Pisces: Pomacentridae) use test eggs to choose good fathers. Anim Behav 79:237-242

Marconato A, Bisazza A (1986) Males whose nest contain eggs are preferred by females Cottus gobio L. (Pisces, Cottidae). Anim Behav 34:1580-1582

McVey ME (1988) The opportunity for sexual selection in a territorial dragonfly, Erythemis simplicicolis. In: Clutton-Brock TH (ed) Reproductive success. University of Chicago Press, Chicago, pp $44-58$

Milligan BG (1998) Total DNA isolation. In: Hoelzel AR (ed) Molecular genetic analysis of populations: a practical approach. Oxford University Press, Oxford, pp 28-64

Mobley KB, Jones AG (2009) Environmental, demographic, and genetic mating system variation among five geographically distinct dusky pipefish (Syngnathus floridae) populations. Mol Ecol 18:1476-1490

Moya-Laraño J, Vinkovic D, Allard CM, Foellmer MW (2009) Optimal climbing speed explains the evolution of extreme size dimorphism in spiders. J Evol Biol 22:954-963

Nakamura K, Sekiguchi K (1980) Mating behavior and oviposition in the pycnogonid Propallene longiceps. Mar Ecol Prog Ser 2:163168

Nazareth TM, Machado C (2010) Mating system and exclusive postzygotic paternal care in a Neotropical harvestman (Arachnida: Opiliones). Anim Behav 79:547-554

Oring LW, Colwell MA, Reed JM (1991) Lifetime reproductive success in the spotted sandpiper (Actitis macularia): sex differences and variance components. Behav Ecol Sociobiol 28:425432

Park SDE (2001) Trypanotolerance in West African cattle and the population genetic effects of selection. Dissertation University of Dublin, Dublin

Payne RB (1984) Sexual selection, lek and arena behavior, and sexual size dimorphism in birds. Ornithol Monogr 33:1-53

Philipp DP, Gross MR (1994) Genetic evidence for cuckoldry in bluegill Lepomis macrochirus. Mol Ecol 3:563-569

Raymond M, Rousset F (1995) GENEPOP (version 1.2): population genetics software for exact tests and ecumenicism. J Heredity 86:248-249

Ridley M, Rechten C (1981) Female sticklebacks prefer to spawn with males whose nests contain eggs. Behaviour 76:152-161

Rittschof CC (2010) Male density affects large-male advantage in the golden silk spider, Nephila clavipes. Behav Ecol 21:979985

Rossiter SJ, Ransome RD, Faulkes CG, Dawson DA, Jones G (2006) Long-term paternity skew and the opportunity for selection in a mammal with reversed sexual size dimorphism. Mol Ecol 15:3035-3043

Schulte-Hostedde AI, Millar JS, Gibbs HL (2004) Sexual selection and mating patterns in a mammal with female-biased sexual size dimorphism. Behav Ecol 15:351-356

Shuster SM, Wade MJ (2003) Mating systems and strategies. Princeton University Press, Princeton

Sokal RR, Rohlf FJ (1995) Biometry. Freeman and Co., New York, NY

Sutherland WJ (1985) Chance can produce a sex difference in variance in mating success and explain Bateman's data. Anim Behav 33:1349-1352 
Sutherland WJ (1987) Random and deterministic components of variance in mating success. In: Bradbury JW, Andersson MB (eds) Sexual selection: testing the alternatives. Wiley, New York, pp 209-219

Tallamy DW (2001) Evolution of exclusive paternal care in arthropods. Ann Rev Entomol 46:39-165

Thomas LK, Manica A (2005) Intrasexual competition and mate choice in assassin bugs with uniparental male and female care. Anim Behav 69:275-281

Tomaschko K-H, Wilhelm E, Bückmann D (1997) Growth and reproduction of Pycnogonum litorale (Pycnogonida) under laboratory conditions. Mar Biol 129:595-600

Unger LM, Sargent RC (1988) Allopaternal care in the fathead minnow, Pimephales promelas: females prefer males with eggs. Behav Ecol Sociobiol 23:27-32

Vanpé C, Kjellander P, Galan M, Cosson J-F, Aulagnier S, Liberg O, Hewison AJM (2008) Mating system, sexual dimorphism, and the opportunity for sexual selection in a territorial ungulate. Behav Ecol 19:309-316
Vincent A, Ahnesjö I, Berglund A, Rosenqvist G (1992) Pipefishes and seahorse: are they all sex role reversed? Trends Ecol Evol 7:237-241

Vollrath F, Parker GA (1992) Sexual dimorphism and distorted sexratios in spiders. Nature 360:156-159

Wade MJ (1979) Sexual selecion and variance in reproductive success. Am Nat 114:742-747

Wade MJ, Arnold SJ (1980) The intensity of sexual selection in relation to male sexual behaviour, female choice, and sperm precedence. Anim Behav 28:446-461

Webster MS, Pruett-Jones S, Westneat DF, Arnold SJ (1995) Measuring the effects of pairing success, extra-pair copulations and mate quality on the opportunity for sexual selection. Evolution 49:1147-1157

Weckerly FW (1998) Sexual-size dimorphism: influence of mass and mating systems in the most dimorphic mammals. J Mammal 79:33-52

Williams GC (1966) Adaptation and natural selection: a critique of some current evolutionary thought. Princeton University Press, Princeton 